\title{
ROSSINIJEVE OPERE NA ODRU STANOVSKEGA GLEDALIŠČA V LJUBLJANI
}

\author{
Jože Sivec
}

Mladi Rossini, ki mu je uspelo, da se je že v prvih letih svoje glasbenodramatske ustvarjalnosti prebil med vodilne italijanske operne skladatelje, se je kaj kmalu po svojih prvih uspehih $v$ Italiji začel uveljavljati izven svoje domovine. Vse od leta 1815, potem ko so bila prvič uprizorjena skladateljeva dela v Barceloni, sledimo hitremu vključevanju njegovih oper $v$ evropski gledališki repertoar. Tako se je mladi mojster kmalu razvil $v$ najpomembnejšega italijanskega opernega skladatelja prve polovice 19. stoletja in prerastel $\mathrm{v}$ svetovno pomembno glasbeno osebnost. Prav njemu se mora Italija zahvaliti, da je obdržala na področju opere svojo vodilno vlogo, ko je že grozilo, da jo bo izgubila in morala prepustiti Franciji.

Leto 1816 predstavlja odločilen prodor Rossinija na sever. To leto so ga namreč prvič spoznali $v$ Nemčiji, ko so $v$ bavarski prestolnici peli njegovo »Italijanko v Alžiru (c. Le nekaj mesecev zatem pa je s svojim »Tancredom ( že osvojil cesarski Dunaj. Še isto leto so izvajali njegove opere tudi v Dresdenu in Darmstadtu. V naslednjih dveh letih pa se je Rossinijev sloves na severu še razširil in utrdil. Leta 1817 so izvedli »Italijanko $v$ Alžiru « $v$ Parizu in »Tancredac $v$ Pragi in Petrogradu, leta 1818 pa »Elizabeto $\mathrm{v}$ Londonu. Tako je bila nekako do leta 1820 večina pomembnih evropskih kulturnih središč že seznanljena $s$ kar več operami tega velikega mojstra.

Rossini si je naglo utiral pot tudi na odre avstrijskega državnega prostora. Za Dunajem (1816) in Prago (1817) so sledila mesta kot Brno (1818), Budimpešta (1819), Gradec (1819) in druga ter med temi, kot bomo še nadalje ugotovili, leta 1820 tudi Ljubljana. ${ }^{1}$

Če torej pretehtamo navedene podatke, vidimo, da se je Rossini pojavil na odru Stanovskega gledališča v Ljubljani sicer z majhno zamudo, ki pa je utemeljena glede na takratne splošne ekonomske razmere in še posebej možnosti gledališke dejavnosti pri nas.

Avstrija je $v$ dolgotrajnih vojnah s Francijo utrpela težke izgube in doživela leta 1809 in 1815 popolen finančni bankrot. Inflacija je povzročila obubožanje najširših krogov prebivalstva. ${ }^{2}$

Ta ekonomska izčrpanost države pa se je seveda še vse bolj občutila v že tako gospodarsko šibkejši in bolj eksponirani obrobni pokrajini, kot je bila tedanja Kranjska. Moč stanov je znatno upadla. Denar za vzdrževanje gledališča in gledaliških družb je dotekal $\mathbf{v}$ popolnoma nezadostni 
meri le iz dohodkov hiš gledališkega fonda in plesnih redut. Razen tega se je gledališka direkcija postopoma pogrezala $v$ dolgove in je mogla nuditi impresarijem le majhno denarno podporo ali pa niti te ne. $\mathrm{V}$ svojem težavnem položaju se je obračala na lastnike lož in prijatelje gledališča s pozivi za prostovoljne prispevke, ki pa niso bili zadostni.

Prav v letih, ko so Rossinijeve opere že začele osvajati evropske odre, je bila glasbenodramatska dejavnost v Stanovskem gledališču nastopajočih nemških družb le skromna, a se do tehnično zahtevnejših oper, kot so Rossinijeve, sploh ni povzpela. ${ }^{3}$ Seveda, ko bi $v$ tem času prišli $k$ nam italijanski operisti, ki so bili navadno zagovorniki novosti $\mathrm{v}$ italijanski operni literaturi, bi imeli Ljubljančani tudi najbrž nekoliko prej priložnost, da se spoznajo z Rossinijem. Toda italijanskih gostovanj ni bilo že vse od leta 1812 dalje. ${ }^{4}$ Gledališka direkcija je sicer bila leta $1817 \mathrm{v}$ kontaktu z neko italijansko družbo, ki se je ponudila. Vendar pa do gostovanja ni prišlo, ker zaradi finančne šibkosti ni zmogla plačati zahtevanega daru, in ker subskripcija za prostovoljne prispevke ni dala pozitivnega rezultata. ${ }^{5}$

In tako so morali Ljubljančani počakati na prvo uprizoritev Rossinija še do sezone 1819/20, ko je $v$ Stanovskem gledališču igrala družba Carla Waidingerja. Zdaj se je operno življenje po ddaljši stagnaciji zopet razmahnilo. Cas delovanja Waidingerjeve družbe $(1818 / 20)$ predstavlja nedvomno prvi vzpon nemške operne reprodukcije v Stanovskem gledališču v 19. stoletju. Glasbeni repertoar, ki je postal prav presenetljivo bogat in pester, je vključeval toliko pomembnih novosti, kot jih dotlej še nismo zasledili pri nobeni drugi družbi prvih dveh decenijev 19. stol.

Prva Rossinijeva opera, ki so jo tedaj Ljubljančani poslušali, je bila „Tancred.$^{6}$ Točen datum premiere ni poznan, ker lepak za to predstavo ni ohranjen, medtem ko $v$ časopisju, kot za tisto sezono sploh, tudi ni mogoče odkriti nobene zabeležbe. Vendar pa, kakor je razvidno iz zaporedja listov zbirke gledališskih lepakov $v$ Narodnem muzeju, bi mogla ta biti le 3., 4. ali 5. januarja $1820 .^{?}$

Iz stilizacije naznanila za drugo uprizoritev dne 16. januarja: „Diese mit grösstem Beyfall aufgenommene Oper, wird heute zum zweytenmahle ... dargestellt werden «, bi bilo mogoče sklepati, da je »Tancred ( naše občinstvo že takoj navdušil. Da je moral biti posebno priljubljen, govori dejstvo, da je dosegel tisto sezono največje število uprizoritev: v sorazmerno kratkem razdobju dveh in pol mesecev skupno kar pet. ${ }^{8}$ Naj še nadalje omenim, da je prav »Tancred ( tista Rossinijeva opera, ki jo bomo poslej na programih Stanovskega gledališča najpogosteje srečavali.

Opera »Tancred ( spada v vrsto Rossinijevih resnih oper, od katerih se je do danes na repertoarju ohranil le »Viljem Tell (. Seveda je prevec lahkotnemu in nenavadno naglo ustvarjajočemu Rossiniju često manjkalo izrazne globine, ki jo zahteva drama. V svojem veselem muziciranju je rad šel mimo dramske situacije ali značaja nastopajočih oseb. Tako ni mogel ustvariti na tem področju del, ki bi vsaj kot celota trajno zadovoljila. Vendar pa njegove resne opere z nenavadnim čarom svojih melodij niso navduševale takratne publike nič manj kot komične. Pregled repertoarja Stanovskega gledališča nas tudi privede do zanimive ugotovitve, da 
je bilo pri nas med Rossinijevimi operami izvedenih več kot polovica resnih.

Navzlic temu, da Rossini v svojih resnih operah večinoma ni znal ustvariti kongenialne glasbe dramskemu tekstu, pa mu nikakor ne gre odrekati pomembne zgodovinske vloge, ki jo je imel pri razvoju italijanske resne opere $\mathrm{v}$ prvi polovici 19. stoletja. Bil je seveda vse prej kot reformator, toda tej že ostareli zvrsti je nesporno vcepil novih življenjskih sokov.' Opera »Tancred“ (Benetke 1813) predstavlja prvi prodoren Rossinijev uspeh doma in $v$ inozemstvu. Seveda ni ta mmelodramma eroica $\mathrm{v}$ treh dejanjih po svoji glasbeni izraznosti še nikakršna heroična opera. Tisto, s čimer si je vsepovsod pridobila velike simpatije občinstva, je predvsem originalnost in živahnost njenih melodij. V razvoju Rossinijeve ustvarjalnosti je »Tancred « nedvomno pomembno delo, saj je to prva njegova opera seria, katere melodijska govorica je že pretežno osebna, medtem ko se je še pred tem često naslanjal na Paerja, Mayerja, Generalija in druge. ${ }^{10}$

Naslednjo sezono 1820/21 pa si je Rossini svoje pozicije $v$ repertoarju Stanovskega gledališča še nenavadno okrepil. Že pred koncem leta 1820 je »Vereinigte Schauspieler und Sängergesellschaft der Catharine Anton unter der Leitung des Carl Waidinger( predstavila dve Rossinijevi novosti: »Othellac (30. XI. in 3. XII.) in »Seviljskega brivcac (21. XII.). ${ }^{11}$

)Othelo (Neapelj 1816) je muzikalno ena najvrednejših Rossinijevih resnih oper. Da lje prišla docela $\mathbf{v}$ pozabo, je $\mathbf{v}$ marsičem vzrok nemogoč libreto. Ker marsikje niso prenesli tragičnega izida, so celo samovoljno spremenili konec opere: namesto da Othello Desdemono zadavi, ga nepričakovano prepriča njeno zatrjevanje nedolžnosti; in tako je opera končala s sentimentalnim duetom, vzetim iz neke druge skladateljeve opere. Če se je to morda dogodilo tudi v Ljubljani, viri ne povedo, čeprav nam po drugi strani tu in tam dajejo podatke o raznih neopravičljivih posegih, ki so jih $\mathrm{v}$ Stanovskem gledališču napravili pri izvedbah nekaterih drugih del.

Kar nas $v$ »Othellu“, ako ga primerjamo z drugimi italijanskimi resnimi operami tistega časa, posebno preseneča, so recitativi. Ti so nenavadno plastični in izraziti. Spremlja jih vseskozi ves orkester in ne le godala kot $\mathrm{v}$ leto starejši »Elizabetic. Sploh pa kaže glasba te opere dosti čustvenosti in toliko izrazne moči, kot je vse dotlej mladi skladatelj še ni razkril. ${ }^{12}$ Rossinijev »Othello« je ena od redkih njegovih resnih oper, ki so se sorazmerno dolgo izvajale. Zadnje izvedbe beležimo še daleč v 19. stoletje vse do pojave istoimenske Verdijeve opere. ${ }^{12}$

S »Seviljskim brivcem( (Il barbiere di Seviglia, Rim 1816) pa je prispel na ljubljanski oder prvi primer skladateljeve komične opere, a hkrati tudi njegova največja in sploh ena vrhunskih stvaritev celotne tovrstne svetovne operne literature. Če Rossiniju nikakor ne moremo odrekati historične pomembnosti na področju resne opere, pa moramo priznati, da je znal mojster $\mathrm{v}$ vrsti nekaterih svojih komičnih oper res ustvariti tekstom komedij, ki jih je komponiral, docela kongenialno 
glasbo. In tako predstavljajo prav ta dela trajne vrednosti, ki se niso odtujila tudi današnjemu občinstvu.

Če je bila prva izvedba Rossinijevega dela nekoliko zakasnela, pa se je sedaj Ljubljana časovno glede prvih uprizoritev »Othella“ in »Seviljskega brivca « že $v$ glavnem postavila ob stran vodilnim evropskim glasbenim centrom, ali pa jih je celo prehitela. Tako je na primer „Othello« doživel prvo izvedbo na Dunaju, v Pragi ali Budimpešti leto dni prej, tj. 1. 1819, a zato drugje zopet pozneje, na primer $v$ Berlinu in Parizu 1. 1821 ali $\mathrm{v}$ Londonu 1. 1822. Podobno časovno razmerje se nam pokaže tudi glede izvedb $)$ Seviljskega brivcac(. ${ }^{14}$

Ko pa so bile leta 1821 svečanosti $v$ zvezi z Ljubljanskim kongresom, ki so se pričele $\mathrm{v}$ januarju, so prav Rossinijeve opere prispevale levji delež $k$ repertoarju glasbenih predstav. Italijanska družba Antonia Cunibertija je od sedmih del, ki jih je izvedla, predstavila kar pet Rossinijevih, a med temi razen 》Seviljskega brivca(c same novitete. ${ }^{15}$ Tedaj si je torej pridobil ta italijanski mojster $\mathrm{v}$ repertoarju ljubljanskega Stanovskega gledališča že močno dominanco, ki jo bo, kot bomo videli, nadalje obdržal še dolgo vrsto let. Toliko njegovih oper kot to leto vșega skupaj kar šest — pa niso Ljubljančani $v$ teku ene same sezone poslušali nikdar več.

Rossinijeve opere, ki so bile takrat $\mathrm{v}$ Ljubljani prvič uprizorjene, so bile: »Srečna prevarac (8. in 14. III.), »Italijanka v Alžiru ( (7. IV.), »Pepelkac( (5. in 10. IV.) in »Edvard in Kristina(c (11. V.). Razen tega pa je družba Catharine Antonove 26. III. ponovila $v$ nemškem jeziku še »Othellac.

Medtem ko je komična enodejanka »Srečna prevarac (L'inganno felice, Benetke 1812) še ena od tistih Rossinijevih zgodnjih oper, v katerih se kažejo še močnejši vplivi neapeljske šole, predstavlja »Italijanka v Alžiru c (L'Italiana in Alyeri, Benetke 1813) prvo skladateljevo umetniško dovršeno delo $\mathrm{v}$ komičnem žanru, ki nosi že izrazito individualen stilni pečat. To opero lahko uvrstimo med najboljše njegove komične opere. Eminentna poteza »Italijanke v Alžiru ( je spontanost, svežost in vedrina. Mladost in genialnost sta se le redkokdaj srečneje združili kot v tej operi, ki še danes deluje enako privlačno kot nekoč. ${ }^{16}$

Medtem ko sta navedeni operi, preden sta prišli v Ljubljano, že nekaj let krožili po raznih evropskih odrih, ${ }^{17}$ pa si je nekoliko mlajša wPepellkac (La cenerentola, Rim 1817) prav $v$ tem času utirala pot $v$ evropski repertoar. Tako so jo 1.1820 izvedli na Dunaju in v Londonu. isto leto kot $\mathrm{v}$ Ljubljani $\mathrm{v}$ Budimpešti, a leto kasneje $\mathrm{v}$ Parizu. ${ }^{18}$ Podobno kot )Italijanka $\mathrm{v}$ Alžiruc ima tudi ta komična opera visoko umetniško vrednost in ne privlači nič manj s svojim presenetljivim bogastvom glasbenih misli, s stalno lahkotnostjo, eleganco in šaljivostjo. Posamezne vloge pa so pisane tehnično zelo zahtevno, še mnogo bolj zahtevno kot pri »Seviljskem brivcu(, zaradi česar je težko najti ansambel pevcev, ki bi bil tej operi dorasel; in tu je morda glavni vzrok, da jo kljub vsem njenim kvalitetam le redko slišimo. ${ }^{19}$ 
Četrta novost $v$ repertoarju družbe Antonia Cunibertija »Edvard in Kristina ( $(E d u a r d o$ e Cristina, Benetke, 1819), resna opera v dveh dejanjih, pa je zelo povprečna in spada $v$ vrsto Rossinijevih nepomembnih tovirstnih del. |Glasbo za to opero je skladatelj večinoma prevzel iz dveh svojih prejšnjih oper: )Adelaide ( in »Ricardac, ki predstavljata $v$ njegovem razvoju le korak nazaj. ${ }^{20}$

Takrat imamo tudi prva poročila o izvedbi Rossinijevih oper pri nas. Knez Metternich in njegov spremljevalec publicist Gentz sta se posebej pohvalno izrazila o predstavi »Pepelke(c. )Hlllyrisches Blatt(c omenja »Seviljskega brivca(, )Srečno prevaro( in »Pepelko( le mimogrede, poslednji predstavi italijanskih operistov, operi mEdvard in Kristinac pa posveča obsežnejšo kritiko. ${ }^{21}$ Kot tu beremo, je uprizoritev te opere po sijaju in umetniški popolnosti prekosila vse prejšnje predstave gostovanja in dosegla veliko odobravanje občinstva. Poročevalec pripominja, da kaj takega še ni bilo videti na našem odru. Vse kaže torej, da so bile izvedbe Rossinija v času Ljubljanskega kongresa na nenavadno visoki umetnišski ravni in glede na gradivo, ki nam je za poznejša leta na razpolago, sploh najkvalitetnejše, kar jih je ta mojster kdajkoli doživel v Stanovskem gledališču.

Če vemo za gotovo, da naslednji operni sezoni nemških gledaliških družb Lorenza Gindla $(1821 / 22)$ in Ferdinanda Rosenaua (1823/24) nista prinesli $v$ repertoar, kar se tiče Rossinija, ničesar novega, ampak le že poznani skladateljevi operi »Tancred« in »Othello« ${ }^{22}$ pa je $v$ tem času slika repertoarja italijanskih operistov manj jasna. Tako o sporedu družbe Lelija Masettija, ki je gostovala spomladi l. $1822,{ }^{23}$ ni nobenih podatkov. Je pa seveda povsem razumljivo, da je ta med ostalim morala peti tudi Rossinija, saj si italijanske operne družbe tedaj skoraj ni mogoče misliti brez njegovih oper. Neposredno gradivo manjka tudi za repertoar gostovanja družbe Masettija naslednjo pomlad. ${ }^{24}$ Vendar pa je tokrat $\mathrm{v}$ gledaliških aktih ohranjen vsaj spored, ki ga je impresarij obetal pred svojim prihodom $v$ Ljubljano. Tu je Rossini najštevilneje zastopan skladatelj. Med ponudenimi operami sso kar tri njegove: Il Turco in Italia, L'inganno felice in Il barbiere di Seviglia. Gotovo je Masetti uprizoril vsaj kakšno od navedenih. Morda pa so Ljubljančani prav tedaj prvič poslušali opero »Turek v Italijic (Il Turco in Italia, Milano 1814). Le-ta sicer po vrednosti ne dosega )Italijanke( ali »Pepellke(, vendar izpričuje dosti originalnosti in jo lahko uvrščamo med mojstrova kvalitetnejša dela. Posebno izvrstni so ansambli, kot kvartet in kvintet ter duet med junakinjo in njenim soprogom. ${ }^{25}$

Povsem jasna slika repertoarja se nam pokaže šele o družbi, ki jo je vodil leta 1824, Giuseppe Fiorani. Tudi ta pa je podobno kot drugi takratni italijanski impresariji dal prednost Rossiniju, saj je v času svojega gostovanja uprizoril kar štiri njegove opere: )Seviljski brivec(, »Tancred (, )Pepelkac in )Srečna prevara (c. ${ }^{26}$

Če torej primerjamo repertoarje nemških in italijanskih družb, ki so igrale $v$ začetku 20-tih let 19. stol. v Stanovskem gledališču, lahko ugotovimo, da je imel Rossini pri enih kot drugih pomembno vlogo. 
Razlika je le ta, da pri Italijanih težišče na Rossiniju izrazito izstopa že tedaj, medtem ko je to opaziti pri Nemcih šele nekoliko pozneje. Seveda pa tudi ne gre prezreti značilnega dejstva, da je bila prav nemška družba tista, đki je prva uvedla Rossinija na ljubljanski oder.

Poslej italijanskih operistov ni bilo vse do leta 1841, in tako so ostale nemške gledališke družine edini posrednik Rossinijevih stvaritev. Zdaj se je pomembnost Rossinija na nemških programih znatno povečala. V času med leti 1825 in 1835 je bila predstavljena še cela vrsta mojstrovih novosti, $v$ posameznih sezonah pa srečujemo kar po tri, štiri ali celo pet njegovih oper.

Prva nemška sezona $v$ znamenju močne Rossinijeve dominance je bila 1. 1825/26, ko je nastopala v Stanovskem gledališču družba Carla Meyerja, ki je bila repertoarno najbogatejša $v$ vsej prvi četrtini 19. stoletja. Značilna poteza repertoarja vseh nemških družb, ki so se $v$ večji meri posvečale izvajanju oper, namreč poudarek na italijanskih in francoskih avtorjih, se je 'še posebno okrepila. Potem ko je Meyer prvo sezono (1. 1824/25) svoje entreprize izvedel »Tatinsko srako« (26. X. 1824) in že poznanega »Othella(, je naslednje leto vključil $v$ svoj repertoar kar pet Rossinijevih oper. Od teh sta bili dve novi: „Aureliano in Palmira (20. XII. 1825) in )La donna del lagoc (17. III. 1826), ostale pa so bile uprizorjene že poprej: »Tancred(, "Tatinska sraka ( in »Italijanka v Alžiru“; slednjo so tokrat peli prvič v nemškem jeziku. ${ }^{27}$ Kot torej vidimo iz navedenega sporeda, goji zdaj nemški impresarij tako rekoč že kar kult tega italijanskega mojstra. Med navedenimi novostmi je umetniško najvrednejša komična opera »Tatinska srakac( (La gazza ladra, Milano 1817), ki predstavlja v dotedanji Rossinijevi ustvarjalnosti nekaj novega po tem, da je njena vsebina napol komična in napol tragična, dosti čustveno poudarjena in pristno ganljiva, kar se vse tudi ustrezno odraža $v$ glasbi. Orkestracija je izdelana tako skrbno, da se je zdelo Rossinijevemu sodobniku Stendhalu celo, da je »Tatinska sraka ç primer opere, kjer je Rossini prvič definitivno žrtvoval svoje pevce orkestru. To delo odlikuje izvrstna glasbena karakterizacija in dramatska enovitost med glasbo in tekstom. "Tatinska srakac je danes, razen če izvzamemo njeno uverturo, žal skoraj docela pozabljena, čeprav tega nikakor ne zasluži. ${ }^{28}$

Resna opera »La donna del lago( sicer kljub nekaterim lepim mestom ne predstavlja trajnejše vrednosti, je pa zanimiva $s$ historičnega vidika, ker najdemo tu prvikrat sledove romantike pri Rossiniju; pravo občutje za naravo in lokalni kolorit, tiste lastnosti, ki bodo pozneje karakterizirale »Viljema Tellac. In če ne pozabimo, da je nekako $v$ tem času romantika že polagoma začela prodirati $v$ repertoar ljubljanskega Stanovskega gledališča, je temú prispevala svoj delež tudi izvedba te opere. ${ }^{29}$ Tretja novost "Aureliano in Palmira (Milano 1813), ena od Rossinijevih zgodnjih resnih oper, pa je docela nepomembno delo, ki ni bilo niti kdove kaj uspešno že $\mathrm{v}$ tistem času. ${ }^{30}$ Edina zanimivost te opere je $\mathbf{v}$ tem, da je bila prvotno zanjo napisana uvertura, ki jo danes poznamo kot znamenito uverturo "Seviljskega brivca(. ${ }^{31}$ 
Po letu 1826 ni v Ljubljani polna tri leta nobene izvedbe Rossinijevih oper. Sțanovsko gledališče je medtem doživelo popolen finančni zlom. Zaradi prevelikega izostanka plačevanja davkov in dolgov je bila maja 1825 uvedena sekvestracija dohodkov gledališkega fonda. Ker ni imela gledališka direkcija več na razpolago niti teh pičlih sredstev, ni tvegala, da prepusti gledališče kateremukoli od impresarijev, ki so se ponujali. Tako je Ljubljana $v$ sezoni $1826 / 27$ ostala brez poklicne gledališke družbe. ${ }^{32}$ Le-to so poskušali nadomestiti s predstavami diletantov, ki so sicer izvedli več oper, toda presenetljivo niti ene Rossinijeve. Kaj je temu vzrok, ni mogoče odgovoriti. Tehnična nedozorelost diletantov najbrž ne, saj so imeli dokaj zahteven repertoar. Vse, kar zasledimo to sezono na repertoarju Rossinija, je le nekaj krajših odlomkov iz njegovih oper, ki so jih peli med dejanji dramskih iger. ${ }^{33}$

Naslednji dve sezoni (1827-1829) je direkcija dala gledališče Carlu Waidingerju. Venidar pa zaradi finančne šibkosti tega impresarija in nezadostne denarne pomoči, ki je bila vezana le na prostovoljne prispevke občinstva, uprizarjanje oper ni bilo mogoče. ${ }^{34}$

Ko pa se je v Stanovskem gledališču jeseni 1. 1829 zopet začelo regularno predstavljanje oper, se je tudi obnovila za nekaj let prekinjena kontinuiteta uprizarjanja Rossinijevih del. Zdaj prehaja zgodovina te ustanove $\mathrm{v}$ 19. stoletju $\mathrm{v}$ obdobje svojega sijajnega umetniškega razcveta, ki je dosegel svoj vrh $\mathrm{v}$ drugi polovici tridesetih let. $\mathrm{S}$ prihodom družbe bratov Glöggl iz Salzburga, se je nemška operna reprodukcija v Ljubljani, katere prvi vapon je bil opazen že neposredno pred kongresom, zopet znatno dvignila. ${ }^{35}$

Podobno kot pred leti Meyerjeva je tudi Glögglova družba nudila obsežen repertoar iz Rosinijeve ustvarjalnosti. V času svojega triletnega delovanja (1829-1832) je predstavila naši publiki vsako sezono po eno pri nas še nepoznano Rossinijevo delo, in to: »Elizabeto( (4. II. 1830), »Grofa Oryja (15. XII. 1830) in »Obleganje Korinta (15. III. 1832). Razen tega pa so tedaj Ljubljančani poslušali še vrsto $v$ Ljubljani že uprizorjenih mojstrovih oper; $1.1829 / 30$ »Tancreda( in »Seviljskega brivea (, 1. 1830/31 »Tancreda (n »Italijanko v Alžiru (s in 1. 1831/32 »Tancreda(, )Seviljskega brivca(, )Tatinsko srako( in )Srečno prevaro(c. ${ }^{36}$

Čeprav ima $v$ teh in naslednjih letih Rossini na repertoarju dokaj močne tekmece $v$ Francozih Boieldieuju, Auberu in Heroldu, ni vendar nihče od teh ogrozil njegove dominance. To pa je uspelo nekoliko pozneje šele Belliniju, čigar opere so bile že tudi prvič uprizorjene za časa Glögglove entreprize in to $\mathrm{v}$ sezoni $1.1831 / 32$.

Od navedenih Rossinijevih novosti sta »Grof Ory ( in »Obleganje Korinta ${ }^{\prime}$ pomembni deli, ki spadata $v$ skladateljevo poslednje, t. j. francosko ustvarjalno obdobje, medtem ko »Elizabeta ( ne predstavlja posebne vrednosti. Partitura opere »Grof Ory“ (Le Comte Ory, Paris 1828) je v celoti prvorazredna. Sicer Rossinijeva glasba tu ne kaže toliko tiste neugnanosti in nezadržljivega toka kot $\mathrm{v}$ )Seviljskem brivcu( ali »Italijanki v Alžiru«, vendar pa zato njena privlačnost ne utegne biti nič 
manjša. Nobena njegova partitura ne izpričuje toliko elegance, pikantnosti in gracioznosti kot prav ta. )Grof Ory ( je plod skladateljevega spoznavanja stila francoske komične opere. Tako se nam torej tu moljster pokaže $\mathbf{v}$ nekoliko drugačni luči kot $\mathbf{v}$ svojih italijanskih komičnih operah, a je pri tem le še ostal samobiten. ${ }^{37}$

)Obleganje Korintac (Le Siège de Corinthe), ki je predelava skladateljeve manj uspešne italijanske opere »Maometto III (, predstavlja stilno nadaljnje zbliževanje $\mathrm{z}$ romantiko. Ne glede na nekaj dolgočasnih mest $v$ prvih dveh dejanjih odlikuje to opero precejšnja dramatska intenzivnost. Zbori so izvrstni in so vedno - bodisi mračni ali živahni vzor dramatskega izraza. Tudi recitativi so ekspresivni. ${ }^{38}$

„Elizabetac (Elisabetta, Neapelj 1815) je prva iz vrste Rossinijevih neapeljskih oper. $\mathrm{Na}$ ljubljanski oder je prispela najbrž $\mathrm{s}$ precejšnjo zamudo, saj so jo $v$ večjih mestih na Zahodu že spoznali med 1.1817 in $1822 .^{39}$ Kvaliteto dramske karakterizacije in spontanosti nadomešča tu prepogosto zunanja efektnost in razkazovanje briljantnosti. »Elizabetac je historično zanimiva le zato, ker je tu Rossini prvič v resni operi v celoti opremil recitative $\mathrm{z}$ instrumentalno spremljavo. Tokrat jih spremljajo le godala, pozneje $\mathrm{v}$ )Othellu (c pa že ves orkester. ${ }^{40}$

Tudi v naslednjih dveh sezonah 1. 1832/33 (entrepriza Neufeld \& Börnstein) in 1. 1833/34 (entrepriza Amalije Mašek) je ostala slika repertoarja, kar se tiče Rossinija, ista. V vsaki od navedenih sezon vodi italijanski mojster s štirimi deli, med katerimi so Ljubljančani poslušali dve novosti: »Mojzes v Egiptu« (9. III. 1833) in »Viljem Tell، (4. I. 1834). ${ }^{41}$

mojzes v Egiptu“ (Mose in Egitto, Neapelj 1818) je starejša verzija Rossinijeve opere na biblično vsebino, ki obravnava boj med Judi in faraonom in so jo večinoma $v$ večjih evropskih mestih uprizorili že $\mathrm{v}$ začetku dvajsetih let. ${ }^{42}$ Ta opera spada vsekakor med najkvalitetnejše skladateljeve resne opere. Karakterizira jo dostojanstvenost in zvišenost, ki se izraža posebno v mogočnih, veličastnih in izvrstno izpeljanih zborih. Tudi vloga orkestra je pomembna. Skladatelj je $s$ predelavo $v$ kasnejši francoski verziji še povečal dramatski efekt in poglobil izraznost naslovnega junaka. Te verzije pa $\mathrm{v}$ Stanovskem gledališču nikoli niso igrali.. ${ }^{43}$ Z „Viljemom Tellom (Guillaume Tell, Paris 1829) pa je naša publika, potem ko je poslušala nekoliko poprej Spontinijevo »Vestalko« (1825) in Auberovo wNemo iz Porticija (c (1831), spoznala že tretjo francosko veliko opero. Tudi »Viljem Tell« še ne sodi med tiste velike opere, ki so žrtvovale dramsko izraznost na račun zunanjega efekta. Baleti, masovne scene in orkestralne pantomime so nedvomno tipično francoski atributi, medtem ko skladatelj $\mathrm{v}$ kantabilni melodiki le ne more zatajiti svojega italijanskega porekla. V tej svoji poslednji mojstrovini se je Rossini izrazno še bolj zbližal z romantiko. Glasbeno razpoloženjsko slikanje prirode, ki daje poseben čar uverturi, prihaja v operi še večkrat prepričljivo do izraza. Žal, da je skladatelj komponiral dokaj šibak libreto, ki je komaj nekaj več kot travestija velike Schillerjeve stvaritve. Toda ne glede na to je vrednost te opere, $\mathrm{ki}$ so jo čislali tudi veliki skladatelji, kot Men- 
delssohn, Berlioz in Wagner, nesporno visoka. Tu sta Rossinijeva instrumentacija in melodija še bolj prefinjeni, medtem ko je postal recitativ še izrazno krepkejši. Seveda pa tudi ta najboljša Rossinijeva resna opera, ki se je obdržala na repertoarju prav do današnjih dni, po svoji kvaliteti ni izenačena. Muzikalno prvi dve dejanji znatno prekašata zadnji. ${ }^{44}$ Zaradi prekomerne dolžine je Rossini 1. 1831 opero reduciral na tri dejanja. Kljub temu da »Viljem Tell ( zaradi sorazmerne kompliciranosti svoje zgradbe ni mogel bogve ogreti občinstva, je že naslednje leto po krstni predstavi v Parizu obšel vrsto pomembnih odrov izven Francije. Tako so ga leta 1830 izvedli v Bruslju, Budimpešti, Londonu, Dunaju, Berlinu, Brnu, Pragi in Frankfurtu. ${ }^{45}$

V Ljubljani so uprizorili opero »Viljem Tell $v$ trodejanski verziji, toda še z naknadnimi skrajšavami, ki so jih zahtevale prilike tukajšnjega gledališča. ${ }^{46}$ Kot izvemo iz kratkega poročila $\mathrm{v}$ )Ilirskem listu(, ta opera tudi našega občinstva ni navdušila. Poročevalec pripisuje to tudi dejstvu, da je tu krenil skladatelj po popolnoma novi poti. Sicer pa je bila izvedba te glasbeno in scensko zahtevne opere prav uspela. ${ }^{47}$

V sezoni 1834/35, ki jo je še nadalje vodila Amalija Maškova, pa je v repertoarju že opazna oslabitev Rossinija, saj sta bili izvedeni le dve njegovi operi ( )Semiramide( in »Tancred(c) nasproti štirim v prejšnji sezoni. ${ }^{48}$ Rossiniju sta tedaj enakovredna Auber in Herold, vsak z dvema operama, razen tega pa se po presledku dveh let zopet pojavi Bellini z opero wMontecchi in Capuletic. Verjetno je treba omenjeno oslabitev Rossinija tudi pripisati zmanjšanju opernega repertoarja in nivoja reprodukcije $v$ Stanovskem gledališču to sezono $v$ zvezi s pojavljajočimi se gmotnimi neprilikami impresarija Amalije Maškove. ${ }^{49}$

Resna opera 》Semiramide“ (Benetke 1823) je bila tokrat prvič uprizorjena $v$ Ljubljani (31. I. 1835). Če vemo, da so to opero peli že v prvih letih po njeni krstni predstavi v Benetkah, na Dunaju, v Münchnu, Londonu in Parizu ali 1. $1826 \mathrm{v}$ Budimpešti, in 1. $1829 \mathrm{v}$ Gradcu, ugotovimo, da je prišla $\mathrm{k}$ nam $\mathrm{z}$ zamudo. ${ }^{50}$ 》Semiramide ${ }^{2}$ je poslednja Rossinijeva italijanska opera. Libreto, ki se naslanja na istoimensko Voltairovo tragedijo, je napisan dosti razumljivo in vsebuje dovolj dejanja. Ne glede na nekatera zelo kvalitetna mesta partiture, pa je tudi Rossinijeva glasba prepogosto neprimerna dramski situaciji. Strah in groza, ki ju imamo $v$ obilici $v$ libretu, sta pogosto povezana $\mathrm{z}$ najbolj trivialnimi glasbenimi mislimi. Skladatelj je tudi podlegel prekomernemu okraševanju pevskih linij. Posebej pa je treba omeniti izvrstno uverturo, ki je $\mathrm{v}$ nasprotju $\mathrm{z}$ večino Rossinijevih uvertur tematsko povezana z opero. ${ }^{51}$

Po letu 1835 pa presenetljivo močno upade pomemibnost Rossinija vं repertoarju Stanovskega gledališča. Oper tega mojstra, ki bi predstavljale za našo publiko novost, poslej več ne srečujemo, a na repertoarju posameznih sezon se navadno ne nahaja več kot le po eno njegovo delo. Minejo pa celo operne sezone, ko Rossini docela izostane; tako 1. 1836/37, $1838 / 39,1843,1852 / 53,1853 / 54$ in $1855 / 56$. 
Nadalje je značilno tudi to, da so italijanski operisti po 1.1835 le še redko izvajali Rossinija. Od vrste italijanskih družb sta ga peli samo dve: otroška družba G. Vianesija spomladi 1. 1844 (Pepelka in Seviljski brivec) in Sacca \& Pozzesi 1. 1842 (Seviljski brivec). To pa je razumljivo spričo dejstva, da so bile kratkotrajne italijanske stagione še dosti bolj kot nemške gledališke družbe usmerjene $\mathbf{v}$ predstavljanje novosti, $v$ tem času predvsem Donizettija in Verdija.

Tako je torej Rossini docela izgubil svoj dominanten položaj, ki ga je imel v repertoarju Stanovskega gledališča v Ljubljani. Prepustiti ga je moral Belliniju in Donizettiju. Rossini je na vrhu svoje slave, star šele 37 let, iz razlogov, ki jih se nikomur ni uspelo povsem objasniti, za vselej odložil pero kot operni ustvarjalec. Prav tedaj pa sta na evropskem opernem obzorju zablesteli imeni omenjenih njegovih rojakov. Ta sprememba se je seveda kaj kmalu odrazila tudi pri nas. Po sezoni 1. 1834/35 sledi nekaj let prevlade Bellinija, po sezoni $1.1840 / 41$ pa prevzame za dolgo vrsto let vodstvo $v$ repertoarju Donizetti, medtem ko ostane poleg njega Bellini še vedno najbolj priljubljen skladatelj.

Razdobje $v$ zgodovini operne reprodukcije Stanovskega gledališča v letih 1820 do 1835 lahko opravičeno imenujemo razdobje Rossinija, saj ni bil v tem času, a prav tako ne tudi poprej ali pozneje noben drug operni skladatelj predstavljen s svojo ustvarjalnostjo ljubljanskemu občinstvu $v$ tolikšnem obsegu kot prav on. Od leta 1820 do 1835 se je zvrstilo na odru Stanovskega gledališča najmanj 16 različnih njegovih del. To število pa utegne biti po vsej verjetnosti še nekoliko večje, ker zaradi pomankljivosti virov repertoar ni docela poznan. Tako Rossini tudi prekaša Donizettija, za katerega sem ugotovil, da je bil $\mathrm{v}$ poznejšem času od leta 1838 pa do preimenovanja Stanovskega gledališča v Deželno gledališče (1861) predstavljen s 14 različnimi operami. V času od 1820 do 1835 je bila najpogosteje izvajana Rossinijeva opera »Tancred ( ${ }^{52}$ Tej pa slede: )Seviljski brivec(,$\left.{ }^{53}\right)$ Italijanka v Alžiru( ${ }^{54}{ }^{\text {}) O t h e l-~}$ loc ${ }^{55}$ in $)$ Tatinska sraka $\left({ }^{56}\right.$ medtem ko zasledimo ostale Rossinijeve opere kvečjemu $\mathrm{v}$ dveh ali $\mathrm{v}$ eni sezoni.

Po 1. 1835 se je podoba repertoarja Rossinija že skoraj dokončno ustalila in dobila nekako tisto fiziognomijo, kot jo ima pravzaprav še danes. Poprej tako priljubljeni »Tancred« je bil uprizorjen le še enkrat (1850/51). 》Seviljski brivec $($ pa je daleč najpogosteje izvajana Rossinijeva opera, edina, ki je ohranila več ali manj kontinuiteto v repertoarju, medtem ko naletimo na nekatere druge le še izjemoma ( "Grof Ory“ 1837/38, »Obleganje Korinta، 1839/40, „Pepelka( 1844, »Tancred» $1850 / 51)$.

Tako je uprizarjanje Rossinijevih oper na odru Stanovskega gledališča nedvomno znatno prispevalo $k$ obogatitvi in oblikovanju stilne podobe repertoarja te ustanove, a hkrati tudi sirilo glasbeno obzorje naše publike, saj je bilo med temi operami precej umetniško pomembnih stvaritev, a tudi nekaj umetnin trajne vrednosti. Stilno so pri nas predvsem utrjevale klasicizem, deloma pa so tudi že pomagale uvajati novo umetnostno smer - romantiko. 


\section{OPOMBE}

${ }^{1}$ Loewenberg A.: Annals of Opera 1597-1940 Cambridge 1943, prim. po letnicah izvedbe Rossinijevih oper.

${ }^{2}$ Hellbling F.: Oesterreichische Verfassungs- und Verwaltungsgeschichte, Wien 1954, str. 332-339.

${ }^{3}$ Comedien-Zettel Sammlung 1815-18 v knjižnici Narodnega muzeja v Ljubljani.

${ }^{4}$ Škerlj S.: Italijanske predstave v Ljubljani od XVII. do XIX. stol., Ljubljana 1936, str. 160-162; Cvetko D.: Zgodovina glasbene umetnosti na Slovenskem, II. zv., str. 202.

${ }_{5}$ Theater-Acten ( $=$ ThA ) Fasc. 74 za 1816-1818, št. 32 v Državnem arhivu Slovenije.

${ }^{6}$ Škerlj S.: ib., str. 163; Dimitz A.: 100 Jahre der Laibacher Bühne, Blätter aus Krain 1865 , str. 74 .

${ }^{7} \mathrm{Na}$ ohranjenem lepaku št. 77 za drugo uprizoritev Tancreda dne 16. jan. je namreč nekdo $\mathrm{v}$ rokopisu dodal opazko, da je ta identičen $\mathrm{z}$ manjkajočim št. 71, ki pa ustreza samo navedenim dnevom.

$\therefore$ Comedien-Zettel Sammlung $(=$ ComZS) za 1819/20. Predstave Tancreda so torej bile: v začetku januarja, 16. I., 20. II. in 19. III.

9 Musik in Geschichte und Gegenwart, geslo Rossini; Lang P. H.: Music in Western Civilisation, New York 1941, str. 834-836; Grout. D. J.: A Short History of Opera, New York 1956, str. 337-340; Grout D. J.: A. History of Western Music, New York 1960, str. 551 in 552.

${ }^{10}$ Toy F.: Rossini, a Study in Tragi-Comedy, New York 1934; Bie O.: Die Oper, Berlin 1920, str. 283; Musik in Geschichte und Gegenwart (= MGG) isto geslo.

${ }^{11}$ Theater-Journal zum Jahreswechsel $1819 / 20$ von 14. Sept. bis incl. letzten December 1820 v ComZS.

${ }^{12}$ Toy F.: ib., 64-67; Bie O.: ib., str. 203-205; MGG isto geslo.

${ }^{13}$ Loewenberg A.: ib.

${ }^{14}$ Loewenberg A.: ib.

${ }^{15}$ ComZS 1820/21; Cvetko D.: ib., str. 203; Škerlj S.: ib., str. 163; Illyrisches Blatt 1821, št. 11, 21.

${ }^{16}$ Toy F.: ib., str. $30-31$ in $43-44$.

17 Loewenberg A.: ib.

18 Loewenberg: ib.

19 Toy F.: ib., str. 68-71; Brockway W., Weinstock H.: The Opera, A History of its Creation and Performance, New York, 1911, str. 142.

${ }^{20}$ Toy F.: ib., str. 78.

${ }^{21}$ Illyrisches Blatt (= IB) 1821, št. 11. 21; Radics P.: Die Entwicklung des deutschen Bühnenwesens in Laibach, Laibach 1912, str. 97; Škerlj S.: ib., str. 162-164; Cvetko D.: ib., str. 203-204.

${ }^{22}$ ComZS $1821 / 22$ in $1823 / 24$.

${ }^{23}$ ThA Fasc. 75 za 1820-1823, št. 200, 210.

${ }^{24}$ ThA, Fasc. 75, Einladung zur Abonnement für die italienische Oper pro 1823 št. 28 in 40.

${ }^{25}$ Toy F.: ib., str. 45.

${ }^{26}$ ComZS 1823/24; Cvetko D.: ib., str. 172.

${ }^{27}$ ComZS 1824-1826.

${ }^{28}$ Toy F.: ib., str. 72-75; Brockway W., Weinstock H.: ib., str. 142-143.

${ }^{29}$ Toy F.: ib., str. 80; Brockway W., Weinstock H.: str. 144; Grout D. J.: A Short History of Opera, str. 338.

${ }^{30}$ Loewenberg A.: ib.

31 Toy F.: str. $44-45$.

32 ThA, Fasc. 78 za 1824-1835, 1825 št. 2, 17, 1826 št. 22, 15, 20.

${ }_{33}$ Fasc. Gledališki tiski, 1826/27 v Državnem arhivu Slovenije.

${ }^{34}$ ComZS 1827-1829; ThA, Fasc. 78, 1827 št. 4, 1828 št. 3, 4, 8.

${ }_{35}$ ThA, Fasc. 79, 1839 št. 306; Fasc. 78, 1833 št. 147, 1830 št. 39, 47, 54, 55; prim. še recenzije $v$ I. B. za leto $1829,1830,1831$. 
${ }^{36}$ ComZS za omenjena leta.

${ }^{37}$ Toy F.: ib., str. 133-136.

${ }^{38}$ Toy F.: ib., str. 91-92, 126-129; Brockway W., Weinstock H.: ib., str. $146-147$.

${ }^{39}$ Toy F.: ib., str. 46; Brockway W., Weinstock H.: ib., str. 136-137.

40 Loewenberg A.: ib.

${ }^{41}$ ComZS za ta leta.

${ }^{42}$ Loewenberg A.: ib. isto geslo.

${ }^{43}$ Toy F.: ib., str. 81-83, Brockway W., Weinstock H.: ib., str. 147; MGG,

${ }^{44}$ Bie O.: ib., str. 285-287; Gregor J.: Kulturgeschichte der Oper, Wien 1950, str. 298; Grout D. J.: ib., str. 314.

${ }_{45}$ Loewenberg A.: ib.

${ }^{46}$ ComZS, lepaka za 4 . in 6. I. 1834.

${ }^{47}$ I. B. 1834 , št. 5 .

${ }^{48}$ ComZS 1834/35.

${ }^{49}$ ThA, Fasc. 79, 1835 št. 203, 204, 216; Fasc. 78, 1834 št. 179, 182, 196.

${ }^{50}$ Loewenberg A.: ib.

51 Toy F.: ib., str. 108-111.

52 uprizorjen v sezonah: 1819/20, 1821/22, 1823/24, 1825/26, 1829/30, 1830/31, $1831 / 32,1832 / 33,1833 / 34,1834 / 35,1850 / 51$.

${ }_{53}$ uprizorjen v sezonah: 1820/21, 1823 (?), 1829/30, 1831/32, 1832/33, $1833 / 34,1840 / 41,1842,1844,1851 / 52,1856 / 57,1860 / 61$.

${ }^{54}$ igrana v letih: 1821, 1825/26, 1830/31, 1833/34.

${ }^{55}$ igran v letih: 1820/21, 1821/22, 1824/25.

56 uprizorjena $v$ letih: $1824 / 25,1825 / 26,1831 / 32$.

\section{SUMMARY}

The first performance of Rossini's music in Ljubljana took place at the beginning of January 1820, when the Carl Waidinger company sang the opera »Tancredœ. Between this time and the year 1835 at least 16 operas of this master were performed at the Ljubljana Theatre. It is posible that the number was somewhat greater, but because of the lack of sources the repertoire is not entirely known. In any event the repertoire of the above mentioned establishment reveals that neither at this particular period, nor indeed, at any other time before or after, was any other composer presented in Ljubljana as often as Rossini.

In the beginning of the 1820 's, when German and Italian opera companies were constantly alternating at the Ljubljana Theatre, the latter performed Rossini's operas to a greater extent than the former. When, however, between 1825 and 1841, there were no Italian opera companies in Ljubljana, the German companies were for a long time the only representatives of this master. Thus, after the year 1824 the importance of Rossini in the German programmes increased noticably. Until the year 1835 the German companies still produced a whole series of the master's new works; in some seasons as many as three, four or even five of his operas were performed.

After the year 1835, however, Rossini completely lost the dominant position which he had held in the repertoire of the Ljubljana Theatre. In was taken over by Bellini and Donizetti. From that time on, only familiar Rossini operas are performed in Ljubljana, and in most seasons only one of his works is given. Sometimes whole seasons go by without a Rossini opera.

Recorded performances of Rossini's operas in the Ljubljand Theatre are as follows: 
Tancred (First performance January 1820), Othello (November 30, 1820), Il barbiere di Seviglia (December 21, 1820), L'inganno felice (March 8, 1821), L'Italiana in Algeri (April 7, 1821), La cenerentola (April 5, 1821), Eduardo e Cristina (May 11, 1821), Le gazza ladra (October 26, 1824), Aureliano in Palmira (December 20, 1825), La donna del lago (March 17, 1826), Elisabetta (February 2, 1830), Le Comté Ory (December 15, 1830), La Siege de Corinthe (March 15, 1832), Mose in Egitto (March 9, 1833), Guillaume Tell (January 4, 1834) and Semiramide (January 31,1835 ). 